\title{
Surface Albedo Variation and Its Influencing Factors over Dongkemadi Glacier, Central Tibetan Plateau
}

\author{
Jie Wang, ${ }^{1}$ Yuhuan Cui, ${ }^{2}$ Xiaobo He, ${ }^{3}$ Jian Zhang, ${ }^{3}$ and Shijiang Yan ${ }^{1}$ \\ ${ }^{1}$ School of Resources and Environmental Engineering, Anhui University, Hefei 230601, China \\ ${ }^{2}$ School of Science, Anhui Agriculture University, Hefei 230601, China \\ ${ }^{3}$ State Key Laboratory of Cryospheric Sciences, Cold and Arid Regions Environmental and Engineering Research Institute, \\ Chinese Academy of Sciences, Lanzhou 730000, China
}

Correspondence should be addressed to Yuhuan Cui; cuiyh@lzb.ac.cn

Received 6 January 2015; Accepted 16 March 2015

Academic Editor: Sven-Erik Gryning

Copyright (C) 2015 Jie Wang et al. This is an open access article distributed under the Creative Commons Attribution License, which permits unrestricted use, distribution, and reproduction in any medium, provided the original work is properly cited.

\begin{abstract}
Glacier albedo plays a critical role in surface-atmosphere energy exchange, the variability of which influences glacier mass balance as well as water resources. Dongkemadi glacier in central Tibetan Plateau was selected as study area; this research used field measurements to verify Landsat TM-derived albedo and MOD10A1 albedo product and then analyzed the spatiotemporal variability of albedo over the glacier according to them, as well as its influence factors and the relationship with glacier mass balance. The spatial distribution of glacier albedo in winter did not vary with altitude and was determined by terrain shield, whereas, in summer, albedo increased with altitude and was only influenced by terrain shield at accumulation zone. During 2000-2009, albedo in summer decreased at a rate of 0.0052 per year and was influenced by air temperature and precipitation levels, whereas albedo in winter increased at a rate of 0.0045 per year, influenced by the level and frequency of precipitation. The annual variation of albedo in summer during 2000-2012 has the high relative to that of glacier mass balance measurement, which indicates that glacier albedo in the ablation period can be considered as a proxy for glacier mass balance.
\end{abstract}

\section{Introduction}

Ice and snow melting is the primary source of water for the inland rivers of western China, and the increased melting of ice and snow is contributing to sea level rise [1]. It is therefore very important to conduct research on glacier mass balance. Under continental climate conditions, glacier mass balance is influenced by surface energy balance processes during the ablation period, and solar radiation provides the primary energy source for glacier melting [2]. Albedo determines the amount of solar radiation energy absorbed by the glacier surface, so it is the key parameter in glacier energy balance models and hydrological models for cold and arid regions. Even small changes in regional climate can cause marked variations of glacier albedo and consequently affect energy balance processes over entire glaciers [3]. Glacier albedo therefore plays a crucial role in glacier mass balance, and variations in albedo caused by changes in climate, as well as aerosols (e.g., black carbon), could change the rate of ice and snow melting, consequently affecting glacier runoff.

In the past, glacier albedo was measured using instruments placed on the glacier, including automatic weather stations (AWS) [4-8] and portable albedometers $[2,9,10]$. Because of the spatiotemporal variability of glacier albedo, measurements from limited points cannot reflect the variability of albedo over entire glaciers for long period. However, ground-based measurements do provide accurate datasets with high temporal resolution and still have a place in glacial research today.

Satellite-based remote sensing systems can acquire images of entire glaciers at regular intervals over time and are valuable for research into the variation of glacier albedo on a broader spatiotemporal scale [11]. Landsat thematic mapper (TM) data, with a high resolution of 30 meters, have been used to investigate the spatial variation of albedo on single glaciers and ice caps $[2,12,13]$. Landsat TM-derived albedos 


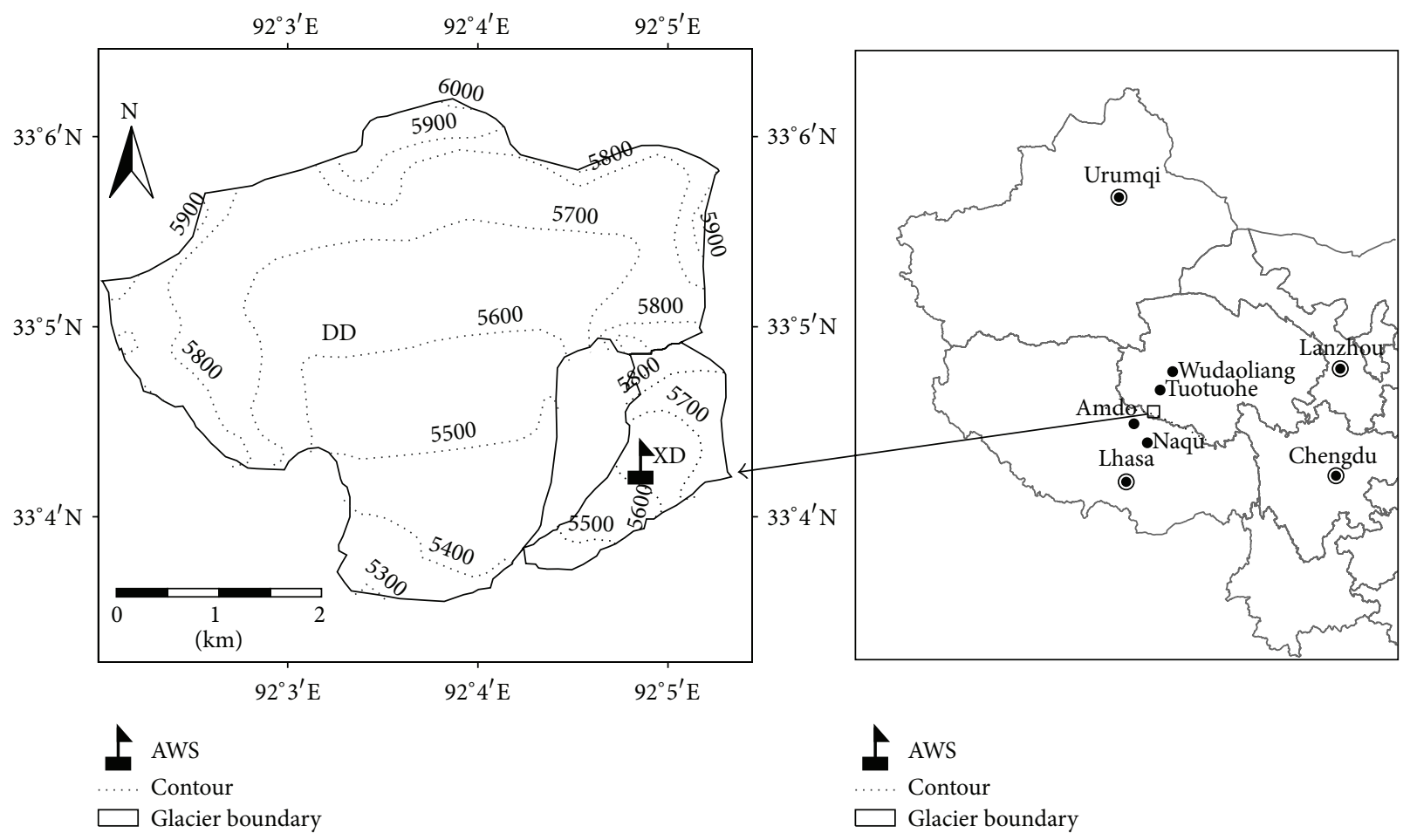

FIGURE 1: The location map of Dongkemadi glacier, indicating the AWS on the glacier and four national weather stations nearby.

have also been incorporated into a distributed mass balance model to calculate mass loss for six glaciers in the European Alps [14]. The high temporal resolution Moderate Resolution Imaging Spectroradiometer (MODIS) albedo product was used to estimate annual anomalies in the surface mass balance of 18 glaciers on Svalbard for the period 2000-2005 [15]. However, there are limitations to the use of remote sensing systems for measuring glacier albedo because the sensors may not be able to acquire data through cloud cover, and data retrieval methods are still being refined. Therefore, it is important to combine ground-based measurements with remote sensing methods for research into the variation of glacier albedo.

The Dongkemadi glacier in the Tanggula Mountains of the central Tibetan Plateau was selected as our study area. We used field measurements on the glacier to verify the accuracy of TM-derived albedo and the beta-test MODIS (MOD10A1) daily albedo product firstly. We then investigated the spatial variation of albedo over the glacier using high spatial resolution TM-derived albedo data and studied the temporal variation of glacier albedo during 2000-2009 using the high temporal resolution MOD10A1 daily albedo product. Lastly, the key factors that affect variation characters of glacier albedo and the influence of glacier albedo on glacier mass balance were further investigated in our research.

\section{Materials and Methods}

2.1. Study Area. The Dongkemadi glacier in the Tanggula Mountains was selected as a representative glacier in a region with a semiarid climate. It is a composite glacier formed by the convergence of a trunk glacier stretching southward and a tributary glacier extending toward the southwest (Figure 1). The trunk glacier, named Da Dongkemadi (DD), covers an area of $14.63 \mathrm{~km}^{2}$, has a length of $5.4 \mathrm{~km}$, a terminal altitude of $5275 \mathrm{~m}$, an average equilibrium line altitude of $5600 \mathrm{~m}$, and a smooth, even surface. The tributary glacier, named Xiao Dongkemadi (XD), covers an area of $1.77 \mathrm{~km}^{2}$, is $2.8 \mathrm{~km}$ long and $5926 \mathrm{~m}$ high at its peak, has an average equilibrium line altitude of $5620 \mathrm{~m}$, and also has a gently sloping, clean surface without surface moraines [16].

The Dongkemadi is classified as a subcontinental glacier [17], and the annual average temperature and precipitation levels are around $-8.4^{\circ} \mathrm{C}$ and $659 \mathrm{~mm}$, respectively. One mass balance year can be divided into two periods: the summer season and the winter season. During the summer season, from May to September, the glacier is under the control of the Indian monsoon, with warm temperatures and high precipitation. During the winter season, from October to April, the weather is under the control of the Westerly Circulation and is sunny, dry, and cold [18].

2.2. Field Observation. In August 2007, an AWS was installed at $33^{\circ} 04^{\prime} 14.24^{\prime \prime} \mathrm{N}, 92^{\circ} 04^{\prime} 53.41^{\prime \prime} \mathrm{E}$, and $5620 \mathrm{~m}$ a.s.l. near the equilibrium line of Xiao Dongkemadi glacier. The AWS was equipped with sensors for temperature, air pressure, humidity, wind speed, and wind direction. It was also equipped with a net radiometer (with upward- and downward-facing pyranometers), and the recording interval was set at $10 \mathrm{~min}$. 
TABLE 1: The difference between TM-derived albedo and AWS-measured albedo.

\begin{tabular}{lcccc}
\hline Date acquired & Path/row & TM-derived values & Measured values & 0.6705 \\
$2008-2-2$ & $137 / 37$ & 0.6283 & 0.8507 & -0.0422 \\
$2008-3-5$ & $137 / 37$ & 0.8308 & 0.6231 & 0.0199 \\
$2008-6-16$ & $138 / 37$ & 0.6613 & 0.7596 & 0.0382 \\
$2008-10-22$ & $138 / 37$ & 0.8217 & 0.6383 & 0.0670 \\
$2008-10-31$ & $137 / 37$ & 0.6737 & 0.6877 & 0.0354 \\
$2008-11-16$ & $137 / 37$ & 0.7113 & 0.7159 & 0.0236 \\
$2008-11-23$ & $138 / 37$ & 0.7713 & 0.6628 & 0.0554 \\
$2008-12-9$ & $138 / 37$ & 0.6730 & 0.5885 & 0.0101 \\
$2009-3-8$ & $137 / 37$ & 0.6538 & 0.6695 & 0.0653 \\
$2009-4-16$ & $138 / 37$ & 0.7096 & 0.6497 & 0.0400 \\
$2009-4-25$ & $137 / 37$ & 0.6866 & 0.5469 & 0.0369 \\
$2009-5-2$ & $138 / 37$ & 0.6211 & 0.7182 \\
$2009-5-18$ & $138 / 37$ & 0.6750 & 0.5425 \\
$2009-8-31$ & $137 / 37$ & 0.5418 & -0.0743 \\
\hline
\end{tabular}

The solar radiation flux measured by the net radiometer was used to calculate the surface albedo at the AWS location, and the distance between the net radiometer and the glacier surface remained close to $1.2 \mathrm{~m}$ throughout the ablation period.

\subsection{Validation of Remote Sensing Albedo Products}

2.3.1. TM-Derived Albedo. Landsat TM images have the advantage of high spatial resolution in the shortwave range of $0.3-4.0 \mu \mathrm{m}$ [19-21]. Therefore TM-derived albedo data can be used to analyze the spatial distribution of albedo over entire glaciers. The process of deriving albedo data from the original images consists of four steps: radiometric calibration, topographic correction, atmospheric correction, and narrowband to broadband conversion. For the last step, the formula developed by Knap et al. [11] is used:

$\alpha_{\text {short }}=0.726 * \alpha_{2}-0.322 * \alpha_{2}{ }^{2}-0.051 * \alpha_{4}+0.581 * \alpha_{4}{ }^{2}$.

Here, $\alpha_{\text {short }}$ represents the shortwave albedo and $\alpha_{2}$ and $\alpha_{4}$ represent the spectral albedo in bands TM 2 and TM 4, respectively.

To verify the accuracy of the above method for retrieving albedo from Landsat TM images, 14 Landsat ETM+ scenes, all acquired around noon and covering the entire glacier, were downloaded from the USGS website (http://glovis.usgs.gov/) during 2008-2009. Shortwave albedo images were retrieved from the downloaded ETM+ scenes according to the above method, and the results were compared with noontime AWSmeasured albedo values by extracting pixel values at the AWS location. Results are shown in Table 1.

The difference between the albedo values retrieved from Landsat TM images (TM-derived albedo) and AWS-measured values ranged from -0.05 to 0.07 (average error $(\mathrm{AE})=$ $0.024, \mathrm{RMSE}=0.046$, and $\left.R^{2}=0.74\right)$. The discrepancy was mainly a result of the atmospheric correction process because, to account for the lack of actual atmospheric parameters when the Landsat TM images were acquired, we used a standard atmospheric model proposed by the $6 \mathrm{~S}$ code (the middle latitude summer/winter model) to estimate atmospheric effects (gaseous absorption by water vapor, carbon dioxide, oxygen, and ozone, and scattering by molecules and aerosols). For use in climate models, the accuracy of surface albedo needs to be \pm 0.05 [22]. Therefore, we found that albedo results retrieved from TM images were accurate enough to be used for research on the spatial variation of albedo.

2.3.2. MOD10A1 Daily Albedo Product. Since February 2000, the MOD10A1 daily product, with a spatial resolution of $500 \mathrm{~m}$, has been distributed by the National Snow and Ice Data Center (NSIDC). The product generates valid shortwave albedo values when a pixel is covered by ice or snow and is cloud-free [8]. Compared with the MCD43A3 albedo product that contains $16 \mathrm{~d}$ of data, the daily MOD10A1 product has the advantage of higher temporal resolution. However, the MOD10A1 daily albedo product is a beta-test product and may contain unsubstantiated errors, especially in output from mountainous regions. It was therefore necessary to verify the product's accuracy over the Dongkemadi glacier.

To account for spatial heterogeneity on the glacier surface, we used spatial scaling transformation technology to upscale high resolution images to moderate resolution, as described by Liang et al. [23]. To determine the accuracy of the MOD10A1 daily albedo product, TM-derived albedo data were first calibrated using ground-based measurements and then aggregated to the MODIS resolution (Figure 2(a)). The difference between calibrated TM-derived albedo and the MOD10A1 daily albedo product is shown in Figure 2(b). The average error was less than $0.05(\mathrm{AE}=0.019$, RMSE $=$ $\left.0.05, R^{2}=0.67\right)$, and the correlation coefficient was higher than 0.8 , so the MOD10A1 albedo product was also accurate 


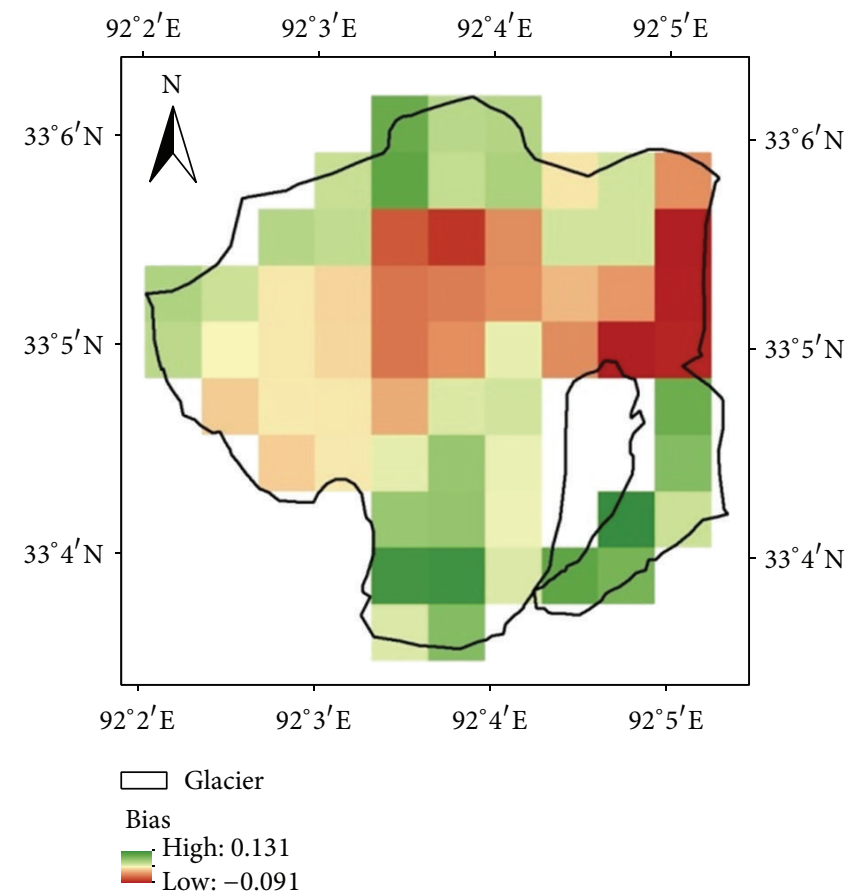

(a)

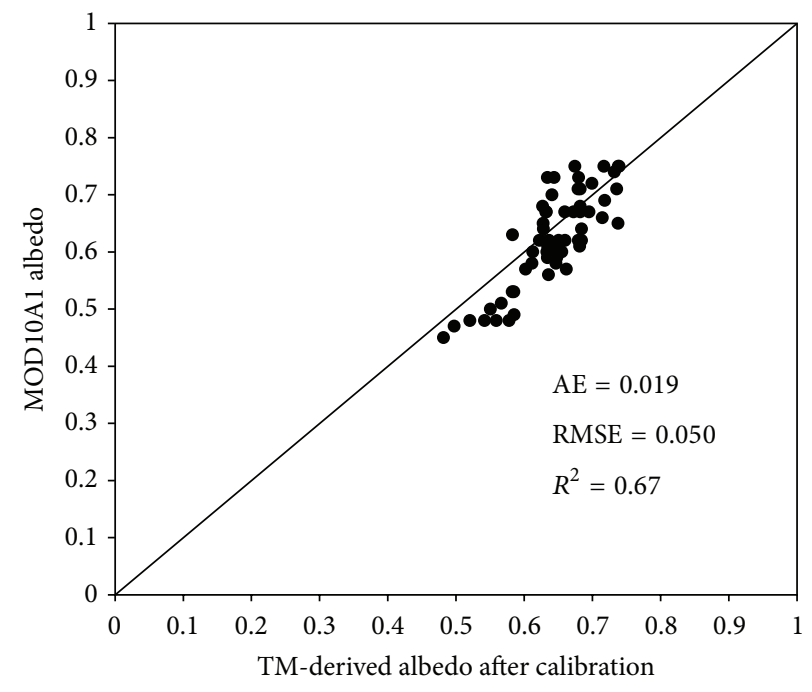

(b)

Figure 2: Comparison between calibrated TM-derived albedo and MOD10A1 albedo. (a) The difference; (b) the scatter diagram (date acquired: 2007-4-28).

enough to be used for research on the variation of glacier albedo.

\section{Results}

3.1. Spatial Variation of Albedo on the Dongkemadi Glacier. Field measurements show that albedo at single points on a glacier changes constantly over time, and this underlies the variation in spatial distribution of albedo over an entire glacier in one year. To investigate the spatial distribution of albedo on the Dongkemadi glacier over one year, we acquired six Landsat TM scenes between October 2006 and September 2007 (three winter scenes and three summer scenes). The glacier albedo was retrieved from the images using the method described in Section 2.3.1, and the retrieved albedo values were divided into four levels (0.0-0.3, 0.3-0.5, 0.5-0.7, and 0.7-1.0) (Figure 3).

Figure 3 shows that the spatial distribution of albedo on the Dongkemadi glacier varied markedly in one mass balance year, and the variation was more complex over the lower part of the glacier than the upper.

In early winter (2006-10-2), the albedo of the glacier did not vary obviously with altitude, with most values between 0.7 and 0.8 , because fresh snow covers the glacier surface at this time of year. There were several albedo values less than 0.7 recorded at high altitude and at the terminal end of the glacier, caused by terrain shield and slight subglacial melting, respectively. In midwinter (2006-12-5), glacier albedo values were similar to those recorded in early winter, and again values did not vary obviously with altitude. Most values were higher than 0.7 , and the low albedo values observed were caused by terrain shield. Compared with October, the albedo values did decrease slightly with altitude because the snowpack becomes older with less snowfall. In late winter (2007-4-28), glacier albedo was lower across the entire surface, but, with most values between 0.5 and 0.7 , variation with altitude was still not obvious.

In early summer (2007-6-22), glacier albedo was only slightly lower than in late winter, with values between 0.5 and 0.7 , and there was little variation with altitude. In midsummer (2007-8-2), glacier albedo values were lower across the entire glacier, but values were clearly related to altitude. Values were higher than 0.5 above $5650 \mathrm{~m}$ a.s.l. and lower than 0.3 below $5580 \mathrm{~m}$ a.s.l.; spatial variation in the upper glacier was caused by terrain shield. Spatial variation was also obvious in late summer (2007-9-19), with values higher than 0.7 above $5500 \mathrm{~m}$ a.s.l. and lower than 0.5 below $5350 \mathrm{~m}$ a.s.l., and albedo also increased with altitude over the lower glacier.

3.2. Annual Variation of Albedo on the Dongkemadi Glacier. It is difficult to conduct field observations on glaciers, and it is therefore difficult to obtain ground-based albedo datasets on glaciers over long period. The long-term albedo datasets provided by the MOD10A1 product make it possible to investigate the annual variation of glacier albedo. We studied the annual variation of albedo on the Dongkemadi glacier 


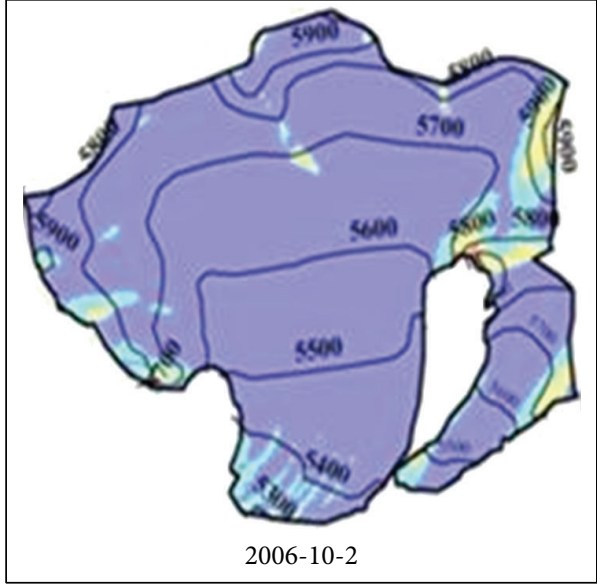

(a)

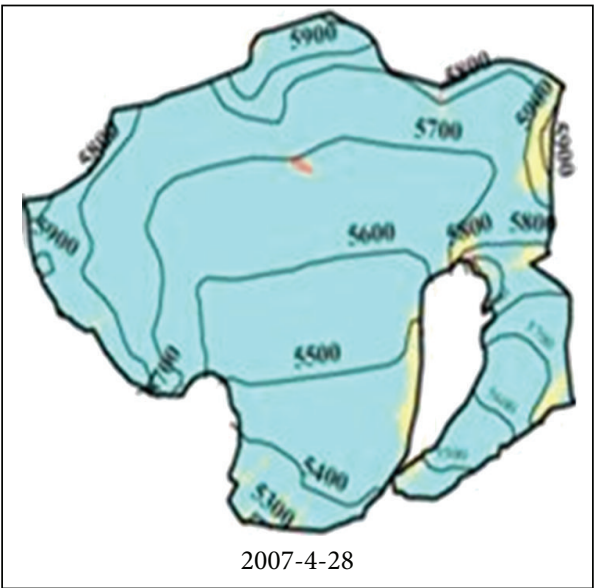

(c)

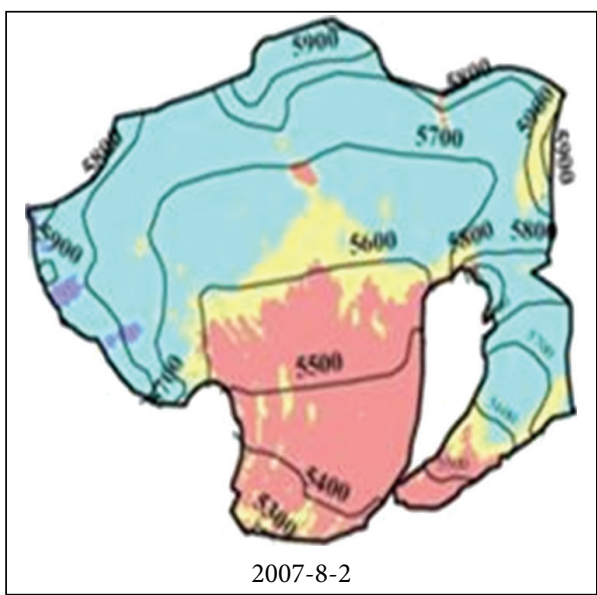

$$
\text { Albedo }
$$$$
\square \text { 0.0-0.3 }
$$

$\square$ 0.3-0.5

$$
\begin{aligned}
& \square \\
& \square 0.5-0.7 \\
& 0.7-1.0
\end{aligned}
$$

(e)

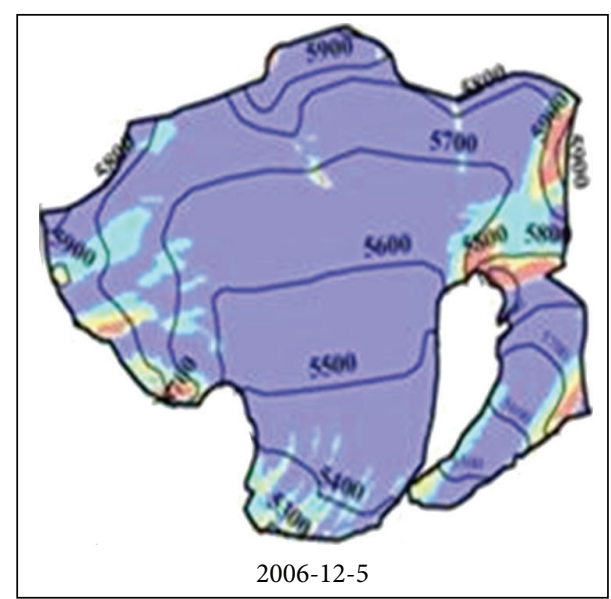

(b)

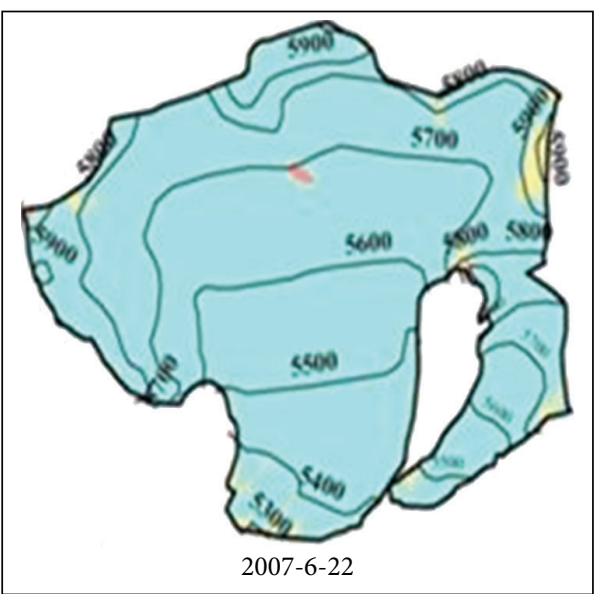

(d)

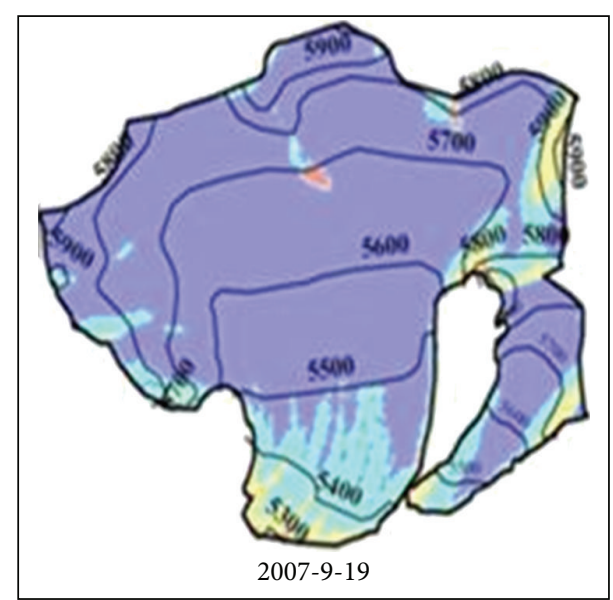

Albedo

$$
\begin{array}{ll}
\square 0.0-0.3 & \square 0.5-0.7 \\
0.3-0.5 & \square 0.7-1.0
\end{array}
$$

(f)

FIGURE 3: The spatial distribution of albedo on the Dongkemadi glacier in one mass balance year from October 2006 to September 2007. Where the solid lines represent the contour lines, and the numbers represent the altitude values of the contour lines (units: meters a.s.l). 


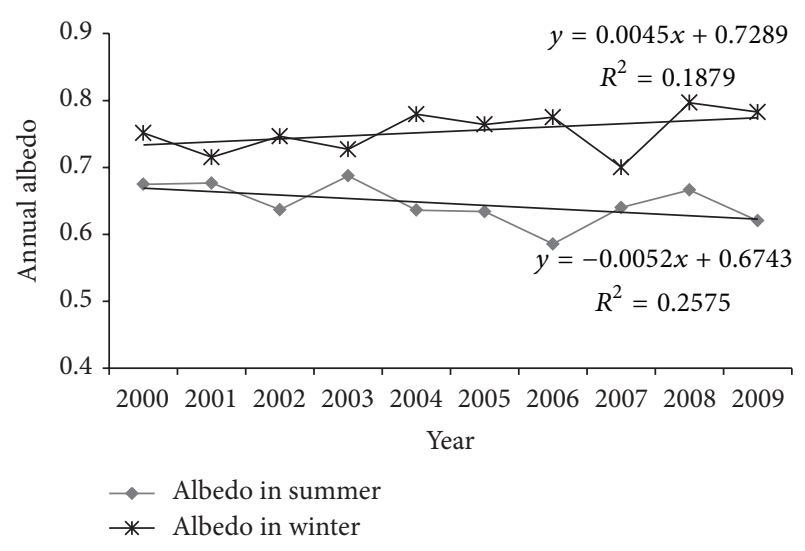

FIgUre 4: Annual variation of albedo on the Dongkemadi glacier from 2000 to 2009 .

over the last decade using MOD10A1 daily albedo products from 2000-2009 and also analyzed the influence of climate change (air temperature and precipitation) on the annual variation of albedo.

Variations in albedo differ across the year; therefore, we divided one mass balance year into summer and winter periods as described above. The annual variation of glacier albedo during these two periods is shown in Figure 4. The figure shows that the annual variation of glacier albedo for the summer period between 2000 and 2009 decreased at a rate of 0.0052 per year, while the variation for the winter period over the same period increased slightly at a rate of 0.0045 per year.

\section{Discussion}

4.1. Influence of Terrain Factors on Spatial Variation of Glacier Albedo. The above results in Section 3.1 showed that the spatial distribution of glacier albedo varied obviously in a mass balance year, using TM-derived albedo datasets. In order to analyze the influence of terrain factors on spatial variation of Glacier albedo, this research divided the glacier into several altitude zones at $50 \mathrm{~m}$ intervals using ASTER GDEM with the resolution of 30 meters; then albedo variations with altitude for the different seasons are analyzed in Figure 5.

Figure 5 shows that glacier albedo increases with altitude generally in the ablation period (2007-8-2, 2007-9-19) and displaying a steep gradient in the center of the glacier, relatively constant above certain altitudes, while glacier albedo in the accumulation period (2006-10-2, 2006-12-5, 2007-1028) presents a fluctuation around the constant values, not relativity to altitude.

Aim to further study on the reason for the fluctuation at the accumulation zone (the part above annual equilibrium line altitude), terrain shield, represents the influence of rugged terrain on sunshine hours, was introduced into our research, and was calculated by ArcGIS software using solar incident angle and Aster GDEM [24, 25]. The glacier was also divided into several terrain shield zones at 0.1 intervals. Figure 6 shows albedo variations with terrain shield for the

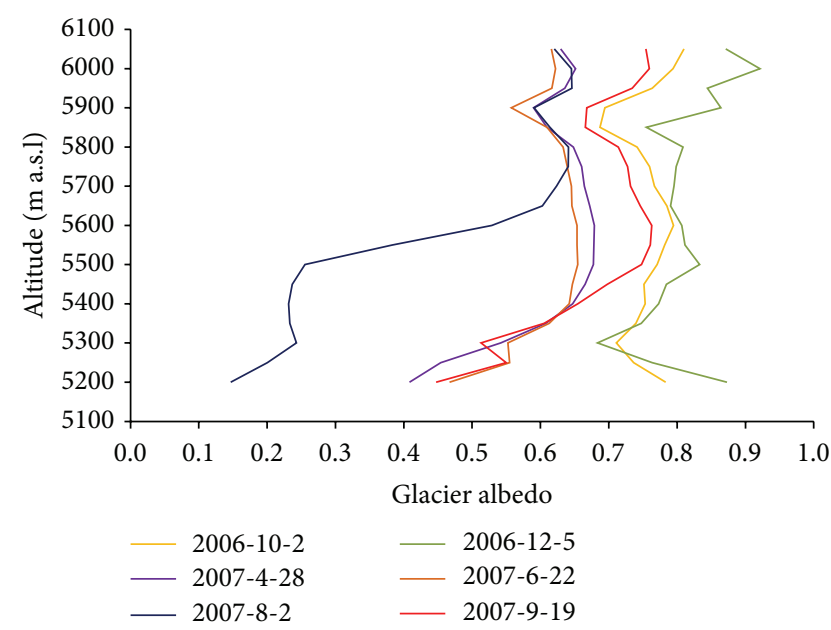

FIGURE 5: Albedo variations with altitude for the different seasons in the period of 2006-2007.

accumulation zone and the ablation zone (the part below annual equilibrium line altitude) on the different months in 2006-2007. From the figure, it can be seen that glacier albedo decreases with terrain shield in accumulation zone, while that in ablation zone is not obvious. The above results indicated that glacier albedo varied little with altitude at the accumulation zone, and terrain shield was the main factor underlying spatial variation. However, glacier albedo clearly increased with altitude at the ablation zone, and terrain shield again influenced the spatial distribution of albedo.

4.2. Annual Variation of Glacier Albedo Responses to Climate Change. Air temperature and precipitation are the main factors controlling the glacier mass balance. The temporal variation of albedo on glaciers is mainly affected by air temperature, snowfall, and the black carbon content in the snow pack $[9,26]$.

In our study, air temperature and precipitation for the Dongkemadi glacier during 2000-2009 were rebuilt using the datasets from four nearby national weather stations (Amdo, Wudaoliang, Tuotuohe, and Nakchu, shown in Figure 1), based on the relationships of air temperature, precipitation between AWS on the glacier and these four national weather stations as described by Gao et al. [27]. Annual variation of glacier albedo was displayed based on the long-term albedo datasets provided by MOD10A1 daily product in the period of 2000-2009.

The annual variations of air temperature, precipitation levels, frequency of precipitation, and glacier albedo in summer and winter are shown in Figures 7 and 8, respectively. The figures show that annual variation of glacier albedo in summer from 2000 to 2009 followed an opposite trend to that of air temperature and a similar trend to that of precipitation levels, but there was no obvious relationship to the frequency of precipitation. The annual variation of glacier albedo in winter from 2000 to 2009 followed a similar trend to precipitation levels and frequency of precipitation, 


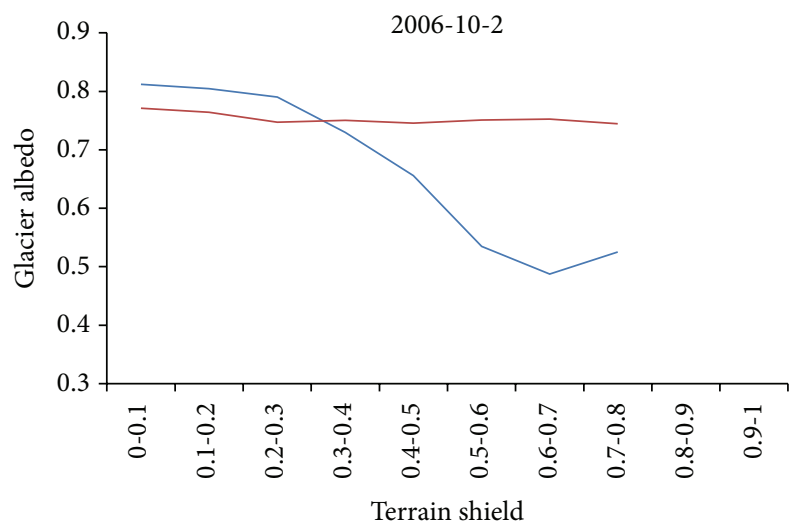

(a)

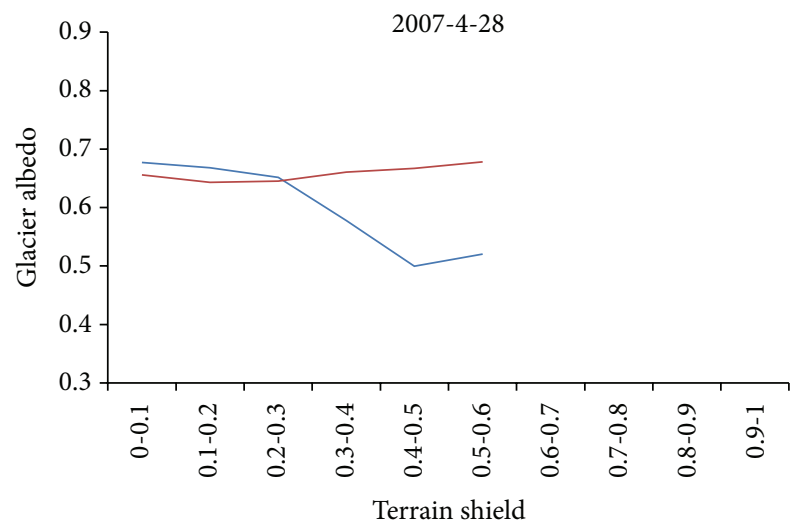

(c)

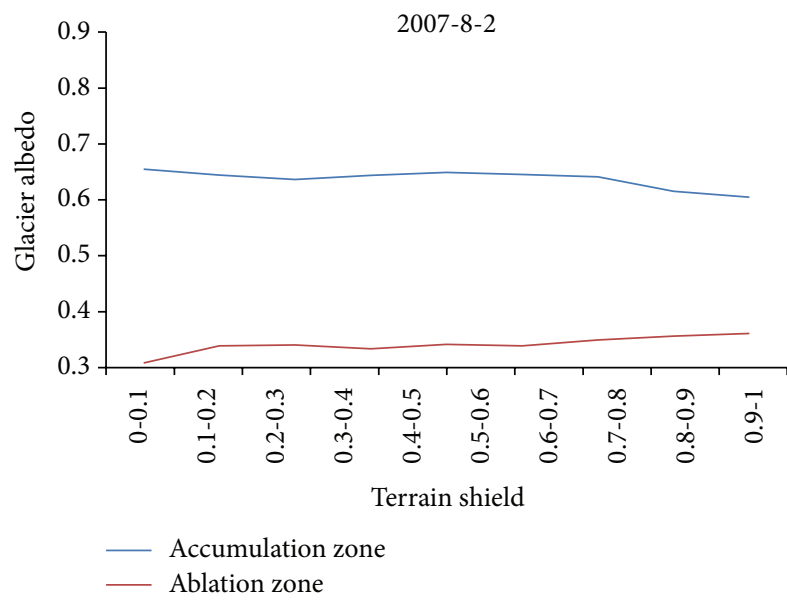

(e)

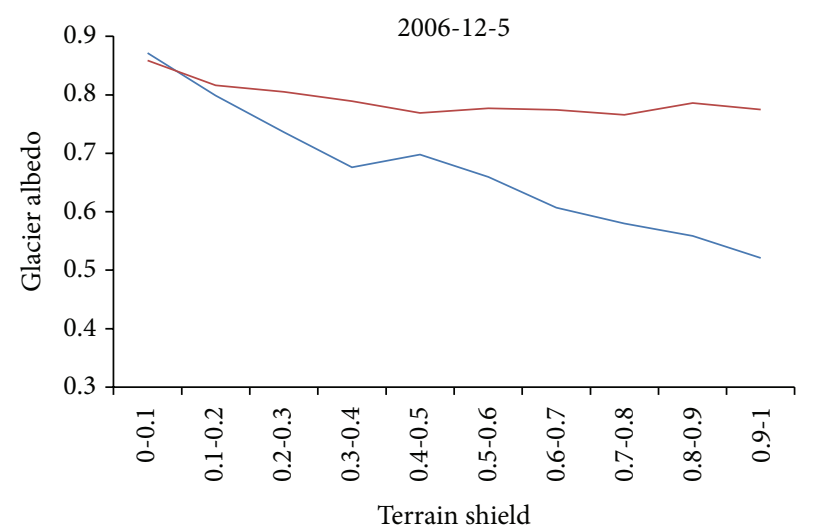

(b)

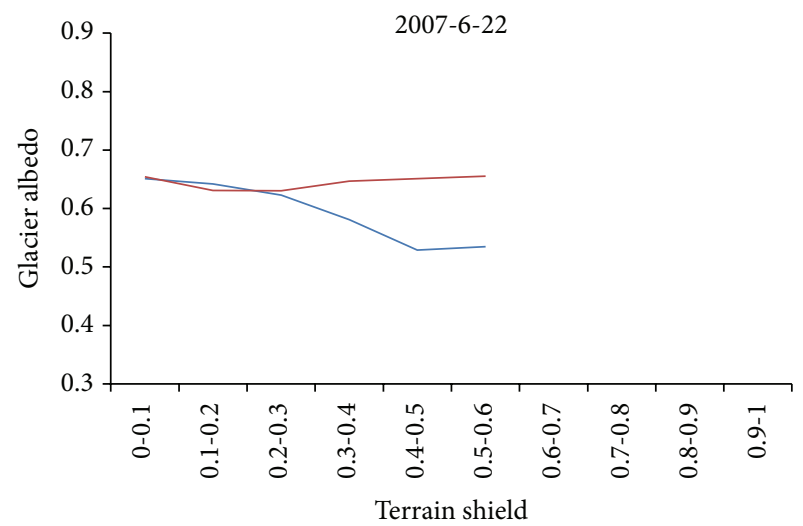

(d)

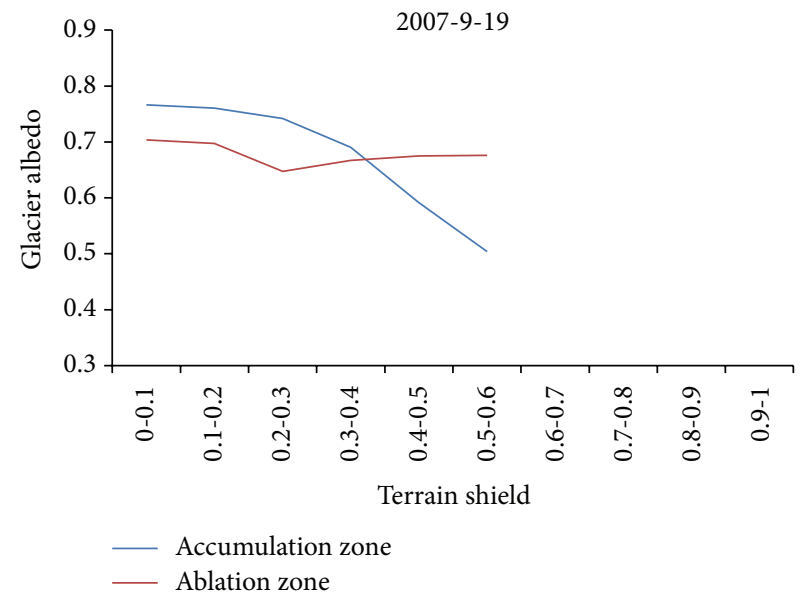

(f)

FIGURE 6: Albedo variations with terrain shield for the accumulation zone and ablation zone on the different months in 2006-2007.

but there was no obvious relationship to air temperature. These results suggest that the annual variation of albedo in summer is influenced by annual changes in air temperature and precipitation levels, while in winter the variation is influenced by the annual change of precipitation levels and the frequency of precipitation.
4.3. Influence of Glacier Albedo on Glacier Mass Balance. As the controlling factor in energy budget on land surface, glacier albedo at the ablation period influences the snow/ice melt rate and then influences glacier mass balance $[26,28]$. Aiming at investigating the influence of glacier albedo on glacier mass balance, we compare the averaged glacier albedo 


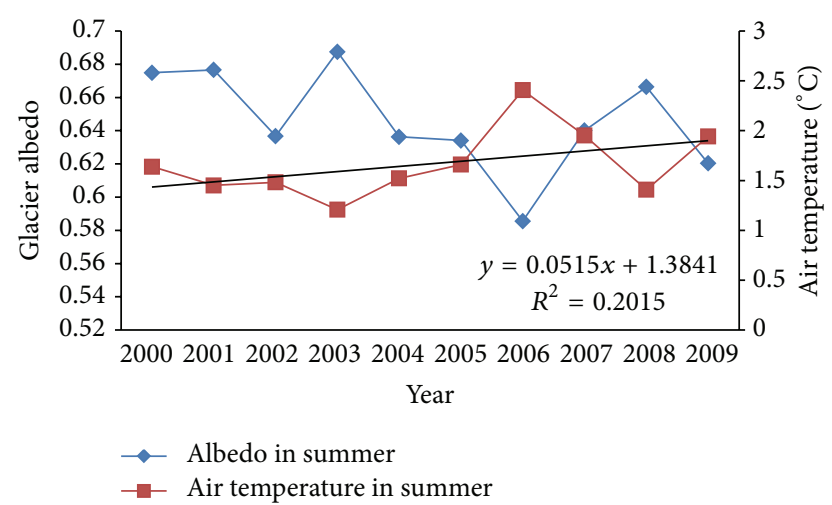

(a)

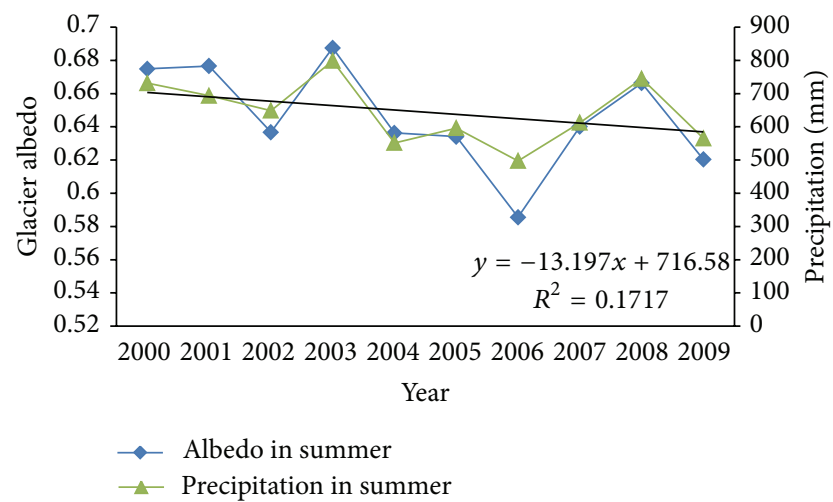

(b)

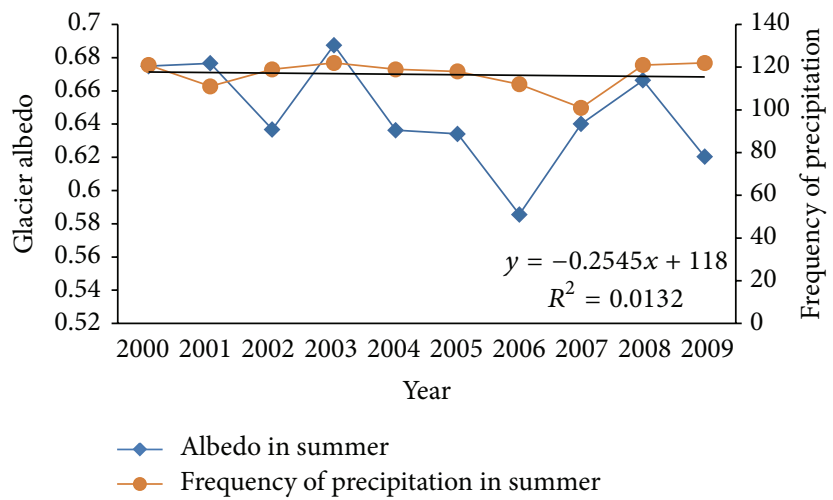

(c)

Figure 7: Annual variations of glacier albedo and meteorological factors in summer during 2000-2009. (a) Air temperature. (b) Precipitation levels. (c) Frequency of precipitation.

in summer to annual mass balance measured by the stakes located on the glacier (shown as Figure 9). Annual variation of glacier albedo was displayed based on the albedo datasets provided by MOD10A1 daily product during the period of 2000-2012.

As shown in Figure 9, the annual variation of albedo in summer was high relative to that of glacier mass balance $(r=0.85, P<0.05)$. The compared result indicates that glacier albedo in summer can be considered as a proxy for glacier mass balance, so glacier albedo from the remotesensing products can be used to monitor the trend of glacier mass balance over a long period.

\section{Conclusions}

Monitoring the variations of mass balance on the glaciers in western China is an important task of the glaciological community. Glacier albedo has a dominant impact on simulating the mass balance of glaciers, as well as on meltwater resources. In this study, we validated the effectiveness of two remote sensing products, Landsat TM-derived albedo and the MOD10A1 albedo product. We then analyzed the spatial variation of albedo on the Dongkemadi glacier in one mass balance year and investigated the factors influencing this variation. We also investigated annual variation of albedo on the Dongkemadi glacier in the last decade and analyzed its influencing factors and the relationship with glacier mass balance.

Both TM-derived albedo and the MOD10A1 albedo product used on the Dongkemadi glacier have reasonable accuracy $\left(\mathrm{RMSE}=0.046, R^{2}=0.74\right.$, and $\mathrm{RMSE}=0.050, R^{2}=$ 0.67 , resp.), and they can therefore be used for research on the variation of glacier albedo. The spatial distribution of glacier albedo in the accumulation period did not vary obviously with altitude and was influenced by terrain shield while in summer albedo increased with altitude and was influenced by terrain shield at the accumulation zone.

During the period 2000-2009, annual variation of albedo in the ablation period decreased at a rate of 0.0052 per year and was related to the annual change in air temperature and precipitation levels, while the annual variation of albedo in the accumulation period increased at a rate of 0.0045 per year and was influenced by the annual change in precipitation levels and the frequency of precipitation. The annual variation of albedo in summer was high relative to that of glacier mass balance measurement, which indicates that glacier albedo in 


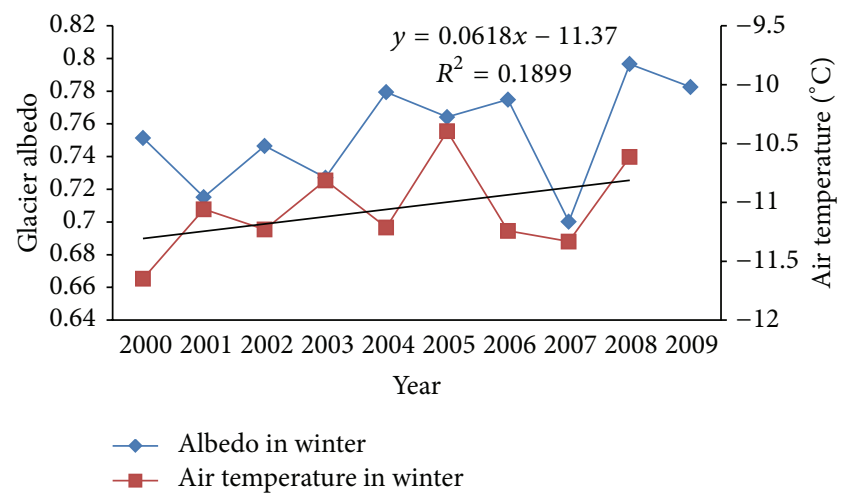

(a)

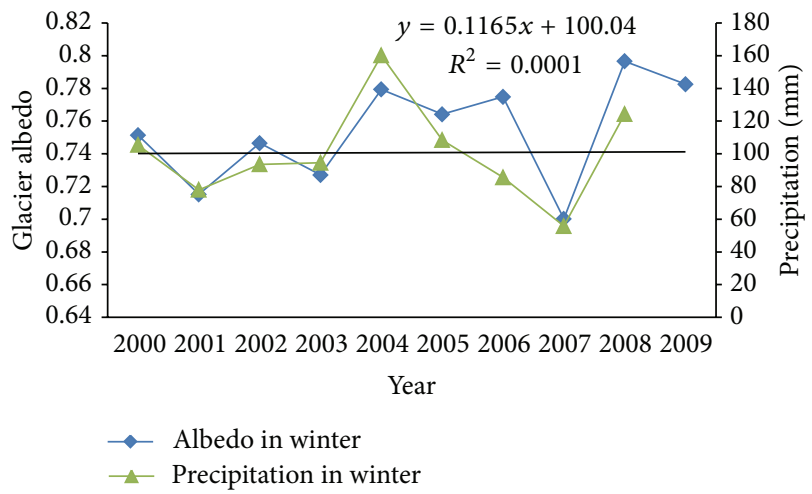

(b)

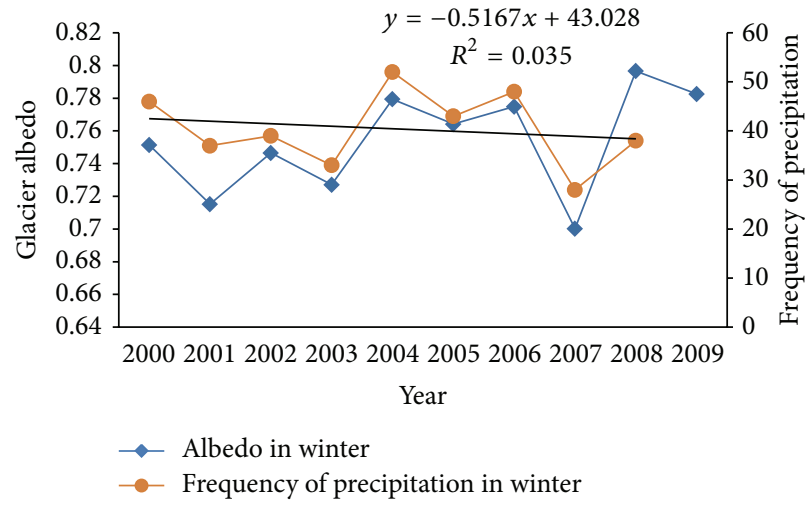

(c)

Figure 8: Annual variations of glacier albedo, meteorological factors in winter during 2000-2009. (a) Air temperature. (b) Precipitation levels. (c) Frequency of precipitation.

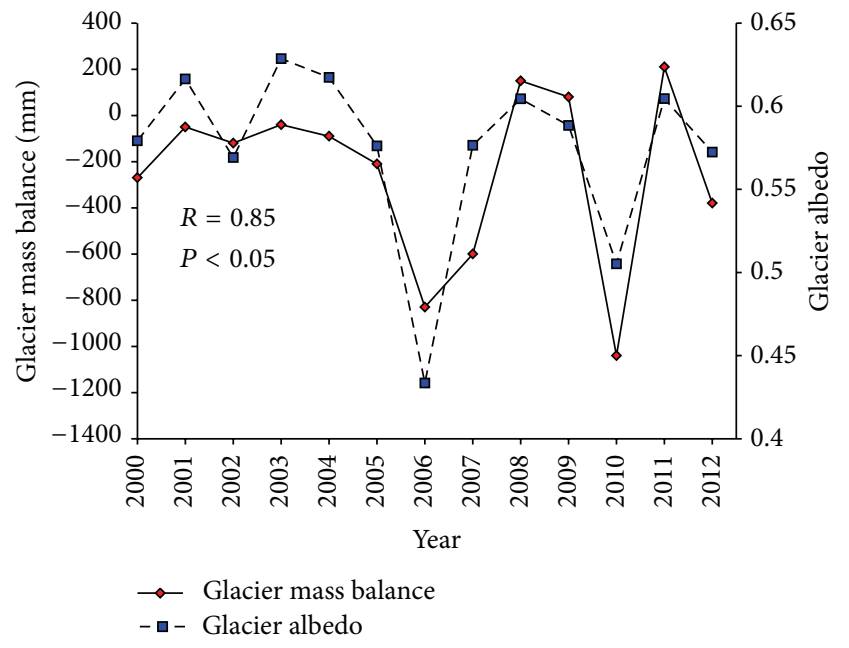

FIGURE 9: Annual variations of glacier mass balance, glacier albedo in summer during 2000-2012.

the ablation period can be considered as a proxy for glacier mass balance.

\section{Conflict of Interests}

The authors declare that there is no conflict of interests regarding to the publication of this paper.

\section{Acknowledgments}

The work was financially supported by the China National Natural Science Foundation (Grants nos. 41401022, 41301422, and 41471001), the Foundation for Young Talents in College of Anhui Province (no. 2013KJT010022), and the Doctoral Research Start-up Funds Projects of Anhui University (no. 32030068). The authors would like to thank Professor Jian Wang and Shiqiang Zhang for their helpful comments and suggestions. Finally, the authors are grateful to the National Snow and Ice Data Center and the United States Geological Survey for the provision of the MOD10A1 product and Landsat TM/ETM+ images.

\section{References}

[1] IPCC, Climate Change 1995: The Science of Climate Change, Cambridge University Press, Cambridge, UK, 1995. 
[2] C. H. Reijmer, W. H. Knap, and J. Oerlemans, "The surface albedo of the Vatnajokull ice cap, Iceland: a comparison between satellite-derived and ground-based measurements," Boundary-Layer Meteorology, vol. 92, no. 1, pp. 125-144, 1999.

[3] J. Xi, W. Ninglian, P. Jianchen et al., "The Albedo on the Qiyi Glacier in Qilian Mountains during the ablation period," Journal of Glaciology and Geocryology, vol. 30, no. 5, pp. 752$760,2008$.

[4] R. C. Hubley, "Measurements of diurnal variations in snow albedo on lemon creek glacier, Alaska," Journal of Glaciology, vol. 2, no. 18, pp. 560-563, 1955.

[5] H. Mannstein, "The interpretation of Albedo measurements on a snowcovered slope," Archives for Meteorology, Geophysics, and Bioclimatology Series B, vol. 36, no. 1, pp. 73-81, 1985.

[6] P. M. Cutler and D. S. Munro, "Visible and near-infrared reflectivity during the ablation period on Peyto Glacier, Alberta, Canada," Journal of Glaciology, vol. 42, no. 141, pp. 333-340, 1996.

[7] U. Strasser, J. Corripio, F. Pellicciotti, P. Burlando, B. Brock, and M. Funk, "Spatial and temporal variability of meteorological variables at Haut Glacier d'Arolla (Switzerland) during the ablation season 2001: measurements and simulations," Journal of Geophysical Research, vol. 109, Article ID D03103, 2004.

[8] J. C. Stroeve, J. E. Box, and T. Haran, "Evaluation of the MODIS (MOD10A1) daily snow albedo product over the Greenland ice sheet," Remote Sensing of Environment, vol. 105, no. 2, pp. 155$171,2006$.

[9] B. Zhongyuan and T. Ohata, "Variations of albedo on the glacier No.1 at the headwater of Urumqi river, Tianshan mountains, during the summer ablation period," Journal of Glaciology and Geocryology, vol. 11, no. 4, pp. 311-324, 1989.

[10] A. E. Tekeli, A. Şensoy, A. Şorman, Z. Akyürek, and Ü. Şorman, "Accuracy assessment of MODIS daily snow albedo retrievals with in situ measurements in Karasu basin, Turkey," Hydrological Processes, vol. 20, no. 4, pp. 705-721, 2006.

[11] W. H. Knap, C. H. Reijmer, and J. Oerlemans, "Narrowband to broadband conversion of landsat TM glacier albedos," International Journal of Remote Sensing, vol. 20, no. 10, pp. 2091-2110, 1999.

[12] R. Koelemeijer, J. Oerlemans, and S. Tjemkes, "Surface reflectance of Hintereisferner, Austria, from Landsat 5 TM imagery," Annals of Glaciology, vol. 17, pp. 17-22, 1993.

[13] E. J. Klok, W. Greuell, and J. Oerlemans, "Temporal and spatial variation of the surface albedo of Morteratschgletscher, Switzerland, as derived from 12 Landsat images," Journal of Glaciology, vol. 49, no. 167, pp. 491-502, 2004.

[14] F. Paul, H. Machguth, and A. Kääb, "On the impact of glacier albedo under conditions of extreme glacier melt: the summer of 2003 in the ALPS," EARSeL eProceedings, vol. 4, no. 2, pp. 139-149, 2005.

[15] W. Greuell, J. Kohler, F. Obleitner et al., "Assessment of interannual variations in the surface mass balance of 18 Svalbard glaciers from the Moderate Resolution Imaging Spectroradiometer/Terra albedo product," Journal of Geophysical Research D: Atmospheres, vol. 112, no. 7, Article ID D07105, 2007.

[16] Y. Zhang, T. Yao, J. Pu et al., "The features of hydrological processes in the Dongkemadi River Basin, Tanggula Pass, Tibetan Plateau," Journal of Glaciology and Geocryology, vol. 19, no. 3, pp. 214-222, 1997.

[17] Y. Shi and S. Liu, "Estimation on the response of glaciers in China to the global warming in the 21st century," Chinese Science Bulletin, vol. 45, no. 7, pp. 668-672, 2000.
[18] J. Pu, T. Yao, and Y. Zhang, "tudy on the relationship between mass balance and climatic factors on the Xiao Dongkemadi Glacier," The Cryosphere, vol. 2, pp. 59-62, 1996.

[19] T. Hilker, M. A. Wulder, N. C. Coops et al., "A new data fusion model for high spatial- and temporal-resolution mapping of forest disturbance based on Landsat and MODIS," Remote Sensing of Environment, vol. 113, no. 8, pp. 1613-1627, 2009.

[20] C. Doña, N. B. Chang, V. Caselles et al., "Integrated satellite data fusion and mining for monitoring lake water quality status of the Albufera de Valencia in Spain," Journal of Environmental Management, vol. 151, pp. 416-426, 2015.

[21] Y. M. Shuai, J. G. Masek, F. Gao et al., "An approach for the long-term 30-m land surface snow-free albedo retrieval from historic Landsat surface reflectance and MODIS-based a priori anisotropy knowledge," Remote Sensing of Environment, vol. 152, pp. 467-479, 2014.

[22] J. Wang and G. Feng, "Discussion on the problems on land surface albedo retrieval by remote sensing data," Remote Sensing Technology and Application, vol. 19, no. 5, pp. 295-300, 2004.

[23] S. Liang, H. Fang, M. Chen et al., "Validating MODIS land surface reflectance and albedo products: methods and preliminary results," Remote Sensing of Environment, vol. 83, no. 1-2, pp. 149$162,2002$.

[24] R. Chen, E. Kang, X. Ji, J. Yang, and J. Wang, "An hourly solar radiation model under actual weather and terrain conditions: a case study in Heihe river basin," Energy, vol. 32, no. 7, pp. 11481157, 2007.

[25] W.-L. Lee, K. N. Liou, and A. Hall, "Parameterization of solar fluxes over mountain surfaces for application to climate models," Journal of Geophysical research, vol. 116, pp. 01101-01113, 2011.

[26] J. Pu, T. Yao, M. Yang et al., "Rapid decrease of mass balance observed in the Xiao (Lesser) Dongkemadi glacier, in the central Tibetan Plateau," Hydrological Processes, vol. 22, no. 16, pp. 2953-2958, 2008.

[27] H. Gao, X. He, B. Ye, and J. Pu, "Modeling the runoff and glacier mass balance in a small watershed on the Central Tibetan Plateau, China, from 1955 to 2008," Hydrological Processes, vol. 26, no. 11, pp. 1593-1603, 2012.

[28] W. Greuell, J. Kohler, F. Obleitner et al., "Assessment of interannual variations in the surface mass balance of 18 Svalbard glaciers from the moderate resolution imaging spectroradiometer /terra albedo product," Journal of Geophysical Research D: Atmospheres, vol. 112, no. 7, Article ID D07105, 2007. 

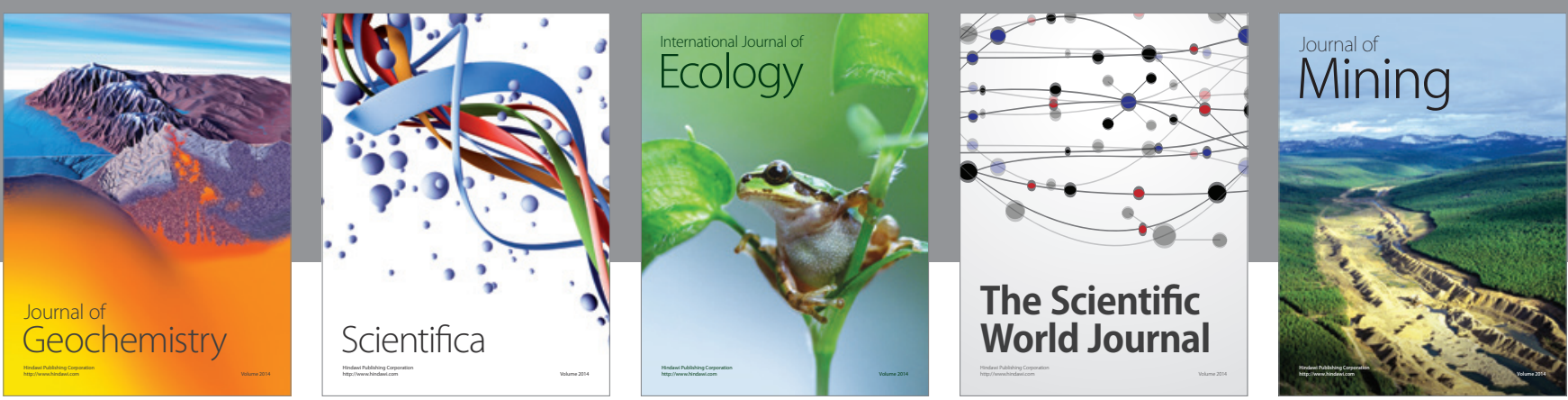

The Scientific World Journal
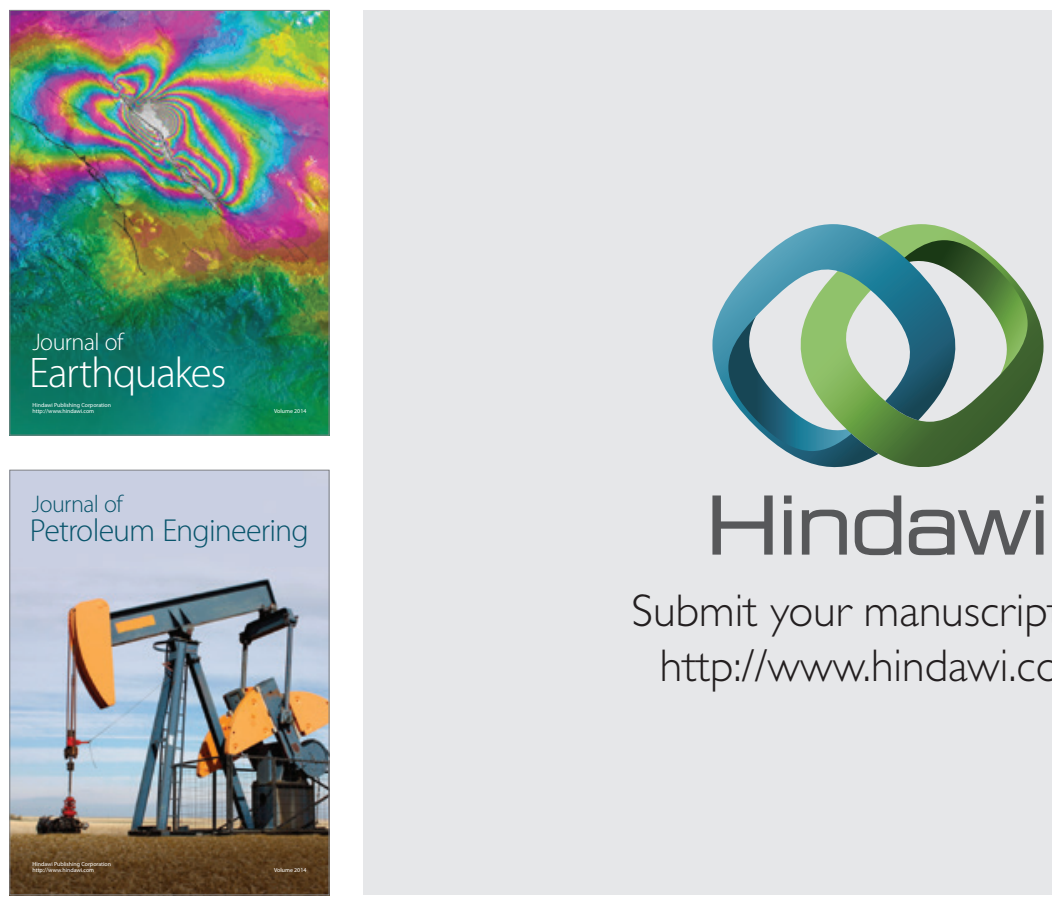

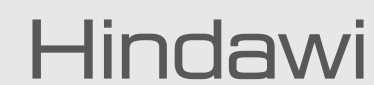

Submit your manuscripts at

http://www.hindawi.com
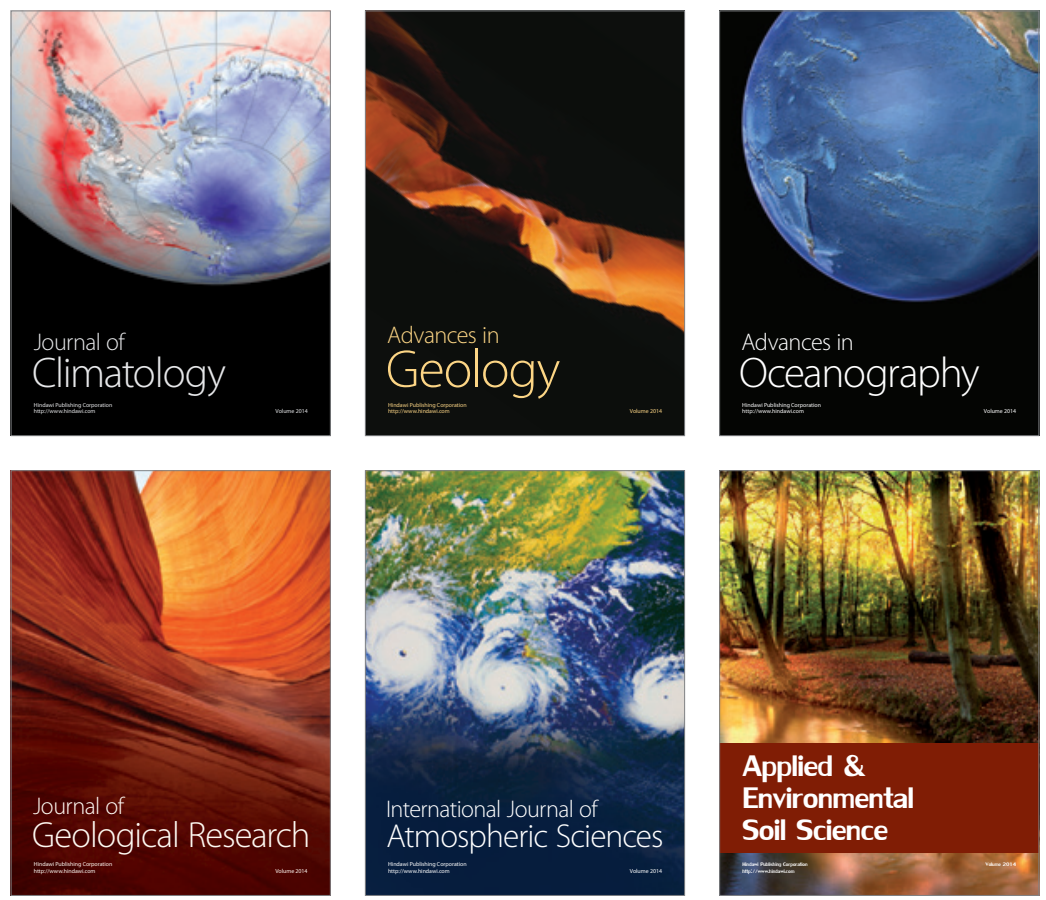
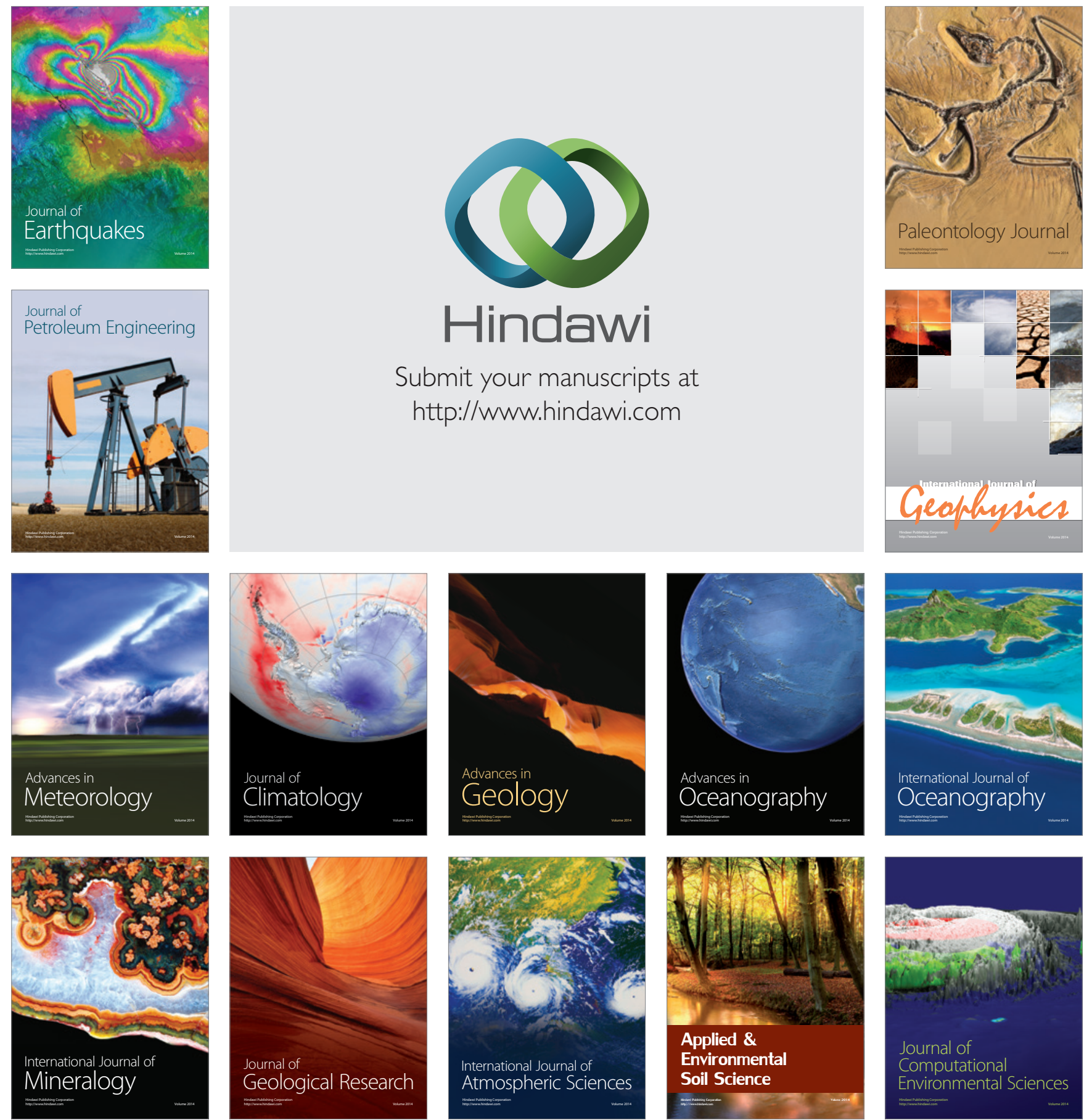